\title{
Subclavian Steal Syndrome Secondary to Atherosclerosis: A Case Report and Review of Literature
}

Sunil Basukala ${ }^{1}$, Bishnu Pathak ${ }^{1}$, Sabina Rijal ${ }^{1}$, Bibek Karki ${ }^{1}$, and Narayan Thapa ${ }^{1}$

${ }^{1}$ Nepalese Army Institute of Health Sciences College of Medicine

December 1, 2021

\begin{abstract}
Subclavian Steal Syndrome (SSS) is a rare vascular syndrome caused due to proximal occlusion or stenosis of subclavian or innominate artery. It is usually asymptomatic but occasionally may present with vertebrobasilar insufficiency and/or upper limb ischemia. Atherosclerosis is the most common cause.
\end{abstract}

\section{Hosted file}

SUBCLAVIAN_STEAL_SYNDROME.docx available at https://authorea.com/users/448970/articles/ 547642-subclavian-steal-syndrome-secondary-to-atherosclerosis-a-case-report-and-reviewof-literature

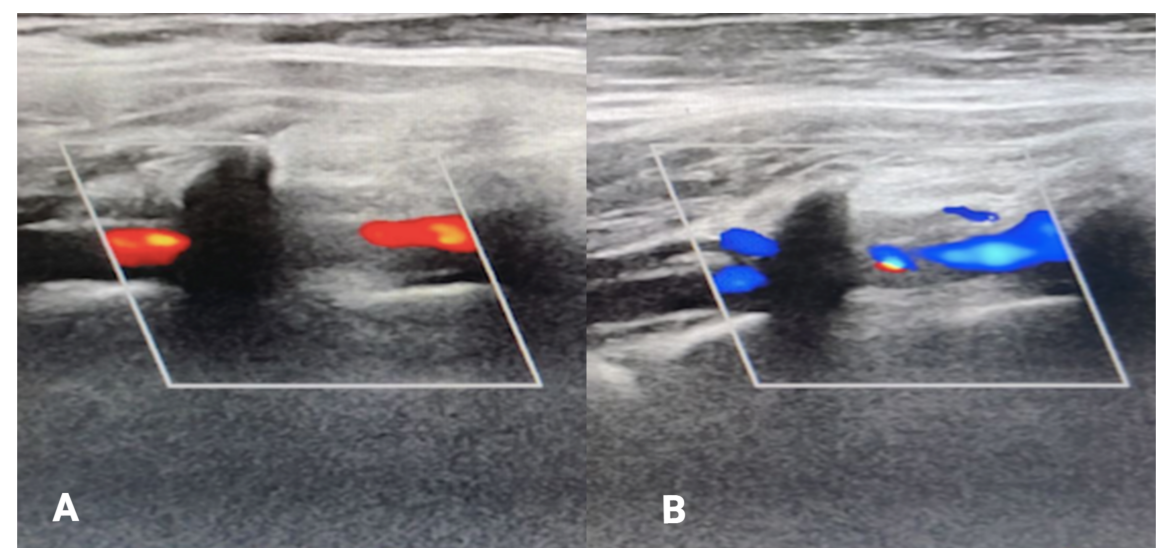




$$
\text { ny }
$$

